\title{
The Human Resource Outsourcing Decision Analysis of the Enterprise
}

\author{
Shao Xiaoyun \\ Jiangxi Normal University,Jiangxi, Jiujiang, China \\ xiaoyu7@163.com
}

Keywords: business outsourcing, human resources outsourcing, AHP analytic hierarchy process, supplier selection

\begin{abstract}
In order to make the human resource management be free from transactional activities, improve the management efficiency of enterprises, and reduce the costs, the human resource management outsourcing begins to prevail. However, being relative to the rapid development of the human resource outsourcing abroad, the domestic human resource outsourcing is still in its infancy. It is relatively short of the theory and method of research on that aspect. On this occasion, whether the outsourcing subject enterprises carry on the human resource outsourcing or not, according to what kind of process we carry on the outsourcing practice, and what problems should be concerned in the process of the implementation, and so on. The current enterprises are so confused with those problems. This paper gives some suggestions with practical significance to the outsourcing subject enterprises who should pay attention to the problems in the process of the human resource outsourcing practice. I hope that the research of my paper can provide the reference for the human resource management of the modern enterprises.
\end{abstract}

\section{Introduction}

Under the new economic era, we clearly know that the human resource is the source of organization to obtain the sustainable competitive advantage. How can we manage the human resource to make its best effect? To solve this problem, firstly, we should know the changes of the contemporary world macroeconomic well, and then take a look at these changes finally bring what kind of changes and challenges to our organization and human resource management.

According to the purpose of this study, we focus on the challenges of human resource management brought by the changes of the macro operating environment. The talent and the talent management are the most deeply influenced by the new economy. Human is the most important resource of the enterprise. Human creates the management of the enterprise, institution, organization, technology, products, capitals, market such as resources. And human also cultivates the core competitive ability of the enterprise. Therefore, human resource management innovation is the key of the enterprise innovation. In the new economic era, there are new changes of the connotation of human resource management, means and operation model. The human resource management workers face with the new challenges.

Although the human resource outsourcing solves the problems of the modern human resource management well, the theoretical research is still in its infancy, especially the outsourcing decision analysis and the quantitative model of the outsourcing service provider selection. The purpose of this paper is to put forward some constructive suggestions for carrying on the human resource of the domestic enterprises through discussing that problem.

\section{The agent of the human resource outsourcing}

The Product of the Socialized Division of Labor. More than 100 years ago, Adam Smith pointed out that the division of labor could improve the proficiency of the workers, save work time, reduce the complexity of labor, and then improve the labor productivity of the enterprises. The 21st century is the era of knowledge economy. The emergence of knowledge economy leads to a large number of the knowledge-based social division of labor and becomes the middle part of industrial 
chain. The human resource management outsourcing is the embodiment of the new division of labor under the new economic era. Theoretically speaking, the essence of the human resources outsourcing is the further extension of the division of labor. When it reduces the complexity of management, it also contributes to increasing the specialization efficiency of the human resources intermediary organizations.

The Need of the Organizational Structure Reform. With the increasingly fierce competition between the enterprises, there is no longer the advantage for the traditional economies of scale in the knowledge economy society. Instead, there are some simplify functions, small scale, high technical content small and flattening enterprise. The simplified function and built core competitive advantages, will make the the part of human resource management functions outsourcing, leave the best main business, and improve the core competitiveness of the organization.

Avoiding the Legal Risk, Saving Costs, Improving Management Efficiency. Human resources outsourcing avoids labor risk, reduces the personnel costs and overall operating costs, and achieves efficient management. It also has very significant role. There is a very significant role for the human resources outsourcing on avoiding labor risk, reducing the personnel costs, and achieving efficient management. To avoid to legal disputes b. To save the cost c. To improve management efficiency

The Need of Strengthening the Core Competencies for the Strategic Role Restructuring of the Department of Human Resource Management. There are both advantages and disadvantages about the human resource management. The organization should be in the full investigation and planning, especially in the case of in-depth understanding of the alternative services to make the outsourcing decisions.

\section{Establishing Discriminant Model of Human Resource Outsourcing Decision}

The Motivation of Establishing Discriminant Model. By analyzing the concept, motivation, advantages and disadvantages above, we know that although outsourcing is increasingly being accepted by the majority of owners by its unique advantages which it can bring to the enterprises, such as low costs, the management with high efficiency, because of the special importance of the human resource functional departments outsourcing subjects can not be blind to make decisions when they consider whether make the some management functions of the organization outsource out. Incorrect decision may cause a variety of risks, and may even lead to the enterprises are involved in the litigation disputes so as to get serious consequences. Therefore, nowadays the human resources outsourcing has become more and more popular, in the process of performing human resources outsourcing decision we should actively explore a set of right outsourcing process which every outsourcing subject enterprise can learn from it to guide the outsourcing business of enterprises.

The Proposal of Discriminant Model. Before we prepare to take the outsourcing and undertake the corresponding risks, managers must have a clear vision to wish the outsourcing to achieve what kind of goal. What's more, they must tell the vision to the outsourcing Committee of the company, the staff of human resources department and other personnel of the company. Only under the situation that the relationship between the company and its service providers is harmonious the functional outsourcing projects of human resource can go well. The cooperative relationship is created in the initial stage of the cooperation. What's more, this kind of cooperative relationship must be cultivated and monitored during the whole period of keeping an agreement. The establishment of quantitative performance measure standards and the periodic inspection of the work benefit are always the best measures to ensure the success of the cooperative relationship.

The evaluation process is also important. In order to encourage outsourcing providers to improve their service quality more effectively, the enterprises must keep monitoring and evaluating any time for the performance of the outsourcing business. If the outsourcers can not achieve the contract goal ultimately, this partnership will be terminated. If the outsourcers realizes or exceeds the goal, the two parties will continue to carry out a new round of cooperation. 
The Process of Enterprise Human Resource Outsourcing Decision and the Management of Cooperative Relationship. 1. The Process of Outsourcing Decision. Aiming at discriminant model of human resource outsourcing decision, the author think that we can divide the human resource outsourcing process into 8 stages for the reference from the outsourcing subject enterprises.

(1) Macro Environment Analysis. If there is no good development environment, the growth and the development of any thing have lost the safeguard. Human resources departments of the enterprises should pay close attention to the development and change of external environment, strengthen environmental analysis, pay attention to the relevant laws and regulations, policies timely, etc. They should choose the right time for the human resources outsourcing.

(2) Establish Special Outsourcing Committee. The outsourcing committee will analyze the human resource activities within the organization to determine the goal of organizing human resource outsourcing and the human resource functions which are suitable for the outsourcing.

The successful sheme of human resource function outsourcing must contain clear short-term and long-term goals. We sugguest that the enterprises should appoint a project team which is formed by the employees from different departments to be responsiblle for the entire outsourcing plan. The team should include the staff from human resources, law, finance, tax laws and other departments. The senior human resource manager undertake the director of project team to be responsible for initiating the research on the problems of outsourcing, looking for related information and data. The project team should clearly know the strategic needs of human resource management from the organization and choose the outsourcing projects reasonably. Under the premise of knowing the organization enterprise culture clearly, the Organization Outsourcing Committee must know clearly present and expected service needs so as to make wise decisions to determine which human resource functions are suitable for the outsourcing.

(3) Cost-benefit Analysis. When we make the human resource outsourcing decision, the consideration about the costs aspect is always the essential factor to decide whether the enterprise is outsourcing or not. The ultimate goal of the enterprise is always profit, so the enterprise leaders with he high level will pay attention to the costs and the corresponding investment return. In general, because outsourcing service providers own the size of the economic advantages and professional advantages, they always take much lower costs than the enterprise to complete the same workload.

(4) Make Prudential Choice for Outsourcing Service Provider. After the basic completion of the preparatory work, the outsourcing committee will proceed to find a suitable outsourcing service provider. Outsourcing is a long-term, strategic cooperation, and the choice and management of outsourcers are also a long-term continuous process. The choice must be carefully inspected and cautiously done. This step is essential in the whole process of outsourcing. If we choose the wrong object, the enterprise may suffer a huge loss. And if we choose the right cooperative partners, it will be a win-win start for the two sides.

(5) Sign a perfect contract.

(6) Communicate well with human resource functional personnel and other staff of the company.

(7) Enter probation period.

(8) Management and cooperation relationship.

(9) After the outsourcing contract is signed, it will enter into the implementation process of the transformation with details. Then the enterprise and outsourcing service providers go into the cooperative period. How to run good cooperative partnership always looks more complicated than its surface.

\section{Problems which We should Pay Attention to in the Outsourcing Practice of Enterprise Human Resource}

Although as a new trend of human resource management development the human resources outsourcing in our country has got more and more attention from the enterprises. It becomes more and more popular in the organization. However, we also have to admit that not all cooperations can successfully achieve the desired result. The organization will find that even though we use the model proposed by the paper scientifically and cooperate with most famous outsourcing service 
providers, there may also be many unexpected sudden problems in the process of outsourcing execution so as to make the final result not so ideal. Because the outsourcing in our country starts late mainly, outsourcing practice happens earlier than outsourcing theory, there are many risks in the implementation specially. Speak essencially, the reason why the fixed goal of human resource outsourcing is difficult to achieve is that it is inseparable with these risks. In the daily management activities, although the enterprise can not completely avoid the risks they face, they can make the results be controlled in the expected range is they pay attention to these risks. Therefore, the author reminds every outsourcing subject enterprise in the paper finally that in the whole process of human resource outsourcing practice, in addition to we should strictly follow the standard human resource outsourcing program, both cooperative parties must also always pay attention to the following several common problems.

(1) Be alert to the changes of external laws and regulations.

(2) Suggest to establish the human resources outsourcing Committee to be specifically responsible for the outsourcing project

(3) When we determine the outsourcing project, we should clear our own needs, and prevent the leakage of confidential at the same time.

(4) Communicate with the staff actively and extensively.

(5) We must be very cautious when we select outsourcing service providers.

(6) Review the cultural compatibility of the two companies.

(7) Pay attention to the costs change any time.

(8) Maintain proactive communication and supervision with the cooperators to prevent the outsourcing project being out of control.

(9) Beware of the decline of enterprise own human resources management ablity to form the dependence on outsourcing.

Human resource outsourcing relationship management is a long-term process, and is a virtuous circle with continuous multi-communication. The ultimate goal is all to achieve the successful implementation of human resource outsourcing. Outsourcing committee should be able to effectively control the progress and the condition of outsourcing implementation and establish routine reporting system, and establish effective information communication channels between the companies and the outsourcers, and build effective cooperation mechanism. All these mentioned above are ties to maintain a long-term outsourcing partnership between the outsourcing enterprises and outsourcing service providers.

\section{Conclusion}

As a kind of strategical management method of reducing costs and improving the core competitiveness of enterprises, from its generation to today enterprises business outsourcing strategy has been developed from the initial information technology, manufacturing and other outsourcing to the financial management, administrative management and human resources outsourcing and other fields. It is said that human resource outsourcing now has become a global big trend. However, being relative to the rapid development of the human resource outsourcing abroad, the domestic human resource outsourcing is still in its infancy. It is relatively short of the theory and method of research on that aspect. On this occasion, whether the outsourcing subject enterprises carry on the human resource outsourcing or not, according to what kind of process we carry on the outsourcing practice, and what problems should be concerned in the process of the implementation, and so on. The current enterprises are so confused with those problems. However, with the introduction of national laws and regulations and the industry becoming more and more standardized, we believe that human resources outsourcing in our contry will also get rapid development.

Since the domestic and foreign research on human resource outsourcing is still in the process of development, the level and emphasis of the research are different, and there must be some disputes in some questions. We need to do further exploration and research in follow-up work and break 
through it. I hope that the future research can be based on the practice of human resource outsourcing in our country to provide the practical and applicable guidance actually.

\section{References}

[1] Uttamkumar M. Kinange,V. Murugaiah. Human Resource Outsourcing: A New Mantra for Business Sustenance[J]. Procedia - Social and Behavioral Sciences,2011,25:.

[2] Vijay Pereira,Valerie Anderson. A longitudinal examination of HRM in a human resources offshoring (HRO) organization operating from India[J]. Journal of World Business,2012,472:.

[3] Maureen G. Butler,Carolyn M. Callahan. Human resource outsourcing: Market and operating performance effects of administrative HR functions[J]. Journal of Business Research,2012,: .

[4] K.Matthew Gilley,Charles R Greer,Abdul A Rasheed. Human resource outsourcing and organizational performance in manufacturing firms[J]. Journal of Business Research,2002,573:.

[5] Gregorio Calderón Hernández. La gestión humana en colombia: características y tendencias de la práctica y de la investigación[J]. Estudios Gerenciales,2007,23103:.

[6] Liudmila Lobanova,Iveta Ozolina-Ozola. Comparative Evaluation of the Practical Areas of Human Resource Management in Lithuania and Latvia[J]. Procedia - Social and Behavioral Sciences,2014,110:

[7] Lihua Zhao,Jiang Li,Jing Li. Empirical Research on Influencing Factors of Human Resources Management Outsourcing Degree[J]. iBusiness,2013,0503:.

[8] David Simmonds,Rebecca Gibson. A model for outsourcing HRD[J]. Journal of European Industrial Training,2008,321:. 